\title{
Pengaruh Store Atmosfer, Persepsi Harga, dan Kualitas Pelayanan terhadap Keputusan Pembelian pada Cafe Wapress JK Pemalang
}

\author{
Manajemen Keuangan
}

\author{
Dimas Maulana Priya Adtya Yudha, Tri Sulistyani, Makmur Sujarwo \\ Fakultas Manajemen dan Bisnis, Universitas Pancasakti Tegal \\ E-mail : Dimasmaulanapriya69@gmail.com
}

\begin{abstract}
Effect of Store atmosfer, Price persepsion and Service Quality on Decisions on Purchasing Cafe Wapress JK in Pemalang. Essay. Faculty of Economics and Business Pancasakti Tegal University.2019. Research Objectives: 1) to find out and analyze the influence of store atmosfer on the decision to buy Cafe Wapress JK Pemalang, 2) to find out the effect of price persepsion on the decision to purchase Cafe Wapress JK Pemalang, 3) to find out the effect of service quality on the decision to purchase Cafe Wapress JK Pemalang, 4) to find out store atmosfer, price persepsion and service qauality simultaneously on the decision to cafe Wapress JK Pemalang. Method of research is survey equal quantitave the population in this study ware consumer who purchased Cafe Wapress JK Pemalang. The sampling technique used was purposive sampling. The data analysis techenique used is Spearman rank correlation, speraman rank correlation significance test, multiple correlation analysis, test of significance of multiple correlation and coefficent of determination analysis. Research results: 1) there is a strong, positive and significant influence of store atmosfer has a significant effect on the decision to purchase in Cafe Wapress JK Pemalang. Barrier can be proven by obtaining value $r_{x y}$ is 0,747, significant value and $Z_{\text {count }}$ value of 6,666 > 1,96, 2) there is a strong, positive and significant influence price persepsion has a significant effect on the decision to purchase in Cafe Wapress JK Pemalang. Barrier can be proven by obtaining value of $r_{x y}$ is 0,702 , significant value and $Z_{\text {count }}$ value of $\left.7,731>1,96,3\right)$ there is a strong, positive and significant influence service quality has a significant effect on the decision to purchase in cafe Wapress JK Pemalang.
\end{abstract}

Keywords: Store atmosfer, price persepsion, service quality, purchasing decision

\begin{abstract}
Abstrak
Pengaruh Store Atmosfer, Persepsi Harga dan Kualitas Pelayanan Terhadap Keputusan Pembelian pada Cafe Wapress JK Pemalang. Skripsi. Fakultas Ekonomi dan Bisnis Universitas Pancasakti Tegal.2019. Tujuan penelitian ini adalah 1) untuk mengetahui dan menganalisis pengaruh store atmosfer terhadap keputusan pembelian Cafe Wapress JK Pemalang, 2) untuk mengetahui pengaruh persepsi harga terhadap keputusan pembelian Cafe Wapress JK Pemalang, 3) untuk mengetahui pengaruh kualitas pelayanan terhadap keputusan pembelian Cafe Wapress JK Pemalang, 4) untuk mengetahui store atmosfer, persepsi harga dan kualitas pelayanan secara simultan terhadap keputusan pembelian pada Cafe Wapress JK Pemalang.. Metode penelitian ini adalah survey dengan pendekatan kuantitatif, populasi dalam penelitian ini adalah konsumen yang melakukan pembelian pada Cafe Wapress JK Pemalang. Adapun teknik pengambilan sempel yang dipakai adalah purposive sampling. Teknik analisis data yang digunakan adalah korelasi rank speraman, uji signifikasi korelasi rank spearman, analisis korelasi berganda, uji signifikasi korelasi berganda dan analisis koefesien determinasi. Kesimpulan penelitian ini adalah 1) terdapat pengaruh yang kuat, positif dan signifikan store atmosfer terhadap keputusan pembelian Cafe Wapress JK
\end{abstract}


Pemalang. Hal tersebut dapat dibuktikan dengan diperolehnya nilai $\mathbf{r}_{\mathrm{xy}}$ sebesar 0,747 dan nilai signifikan $Z_{\text {hitung }}$ sebesar 6,666 > 1,96,2) terdapat pengaruh yang kuat, positif dan signifikan persepsi harga terhadap keputusan pembelian Cafe Wapress JK Pemalang. Hal tersebut dapat dibuktikan dengan diperolehnya nilai $r_{x y}$ sebesar 0,702 dan nilai signifikan $Z_{\text {hitung }}$ sebesar $7,731>1,96,3)$ terdapat pengaruh yang kuat, positif dan signifikan kualitas pelayanan terhadap keputusan pembelian Cafe Wapress JK Pemalang.

Kata kunci: Store Atmosfer, Persepsi harga, Kualitas pelayanan,Keputusan pembelian

\section{PENDAHULUAN}

Persaingan bisnis menjadi salah satu tantangan yang dihadapi para wirausahawan, berbagai macam bidang usaha terus bermunculan di Indonesia baik dalam sektor jasa maupun barang, begitu juga banyak sekali yang menjalankan bisnis di bidang yang sama. Hal ini membuat perusahaan harus mampu bersikap dan bertindak tepat dalam menghadapi persaingan. Pengusaha berupaya dalam mendatangkan pelanggan dan mempertahankan pelanggan guna meningkatkan pembelian guna akhirnya melakukan keputusan pembelian.

Pebisnis mulai menarik konsumen dengan berbagai cara yang mampu memenuhi kebutuhan dan keinginan para konsumen, di era globalisasi ini bisnis yang tak pernah sepi dari kejaran konsumen adalah bisnis kuliner. Bisnis kuliner sekarang mempunyai banyak jenis dari restoran, cafe hingga kedai kopi. Cafe merupakan bisnis kuliner yang menerapkan kesan modern dan nyaman pagi para konsumen, bisnis cafe mulai merambah kota-kota maupun di kabupaten yang ada di Indonesia tak terkecuali Pemalang.

Pemalang mempunyai cafe yang cukup terkenal yaitu Cafe Wapress JK Pemalang yang bertempat di jalan kaligawe, kecamatan taman, kabupaten Pemalang. Cafe Wapress JK Pemalang menawarkan konsep cafe yang modern juga artistik ditambah cafe di kelilingi area persawahan yang menambah kesan sejuk dan nyaman bagi para konsumen. Namun dengan perkembang bisnis yang terus meningkat Cafe Wapress JK Pemalang harus berupaya terus meningkatkan pelayanan, dan persaingan harga yang terus dinamis serta kenyamanan bagi para konsumen.

Cafe Wapress JK Pemalang merupakan salah satu tujuan favorit tempat makan dan minum. Hal ini ditunjukkan dengan jumlah pengunjung yang cukup banyak setiap harinya. Namun seiring dengan banyak nya cafe yang bermunculan dan juga dengan perpindahan cafe yang semula di jalan pemuda dan berpindah di jalan kaligawe sedikit banyak nya membuat gap penjualan, dan mengakibtkan terjadi penurunan jumlah penjualan pada cafe Wapress JK Pemalang dari tahun 2017 sebesar 8.321 menjadi 7.700 di tahun 2018 dan menurun sebesar 621 .

\section{Hipotesis}

H1: Terdapat pengaruh store atmosfer terhadap keputusan pembelian Cafe Wapres JK Pemalang.

$\mathrm{H} 2$ : Terdapat pengaruh persepsi harga terhadap keputusan pembelian Cafe Wapres JK Pemalang.

H3: Terdapat pengaruh kualitas pelayanan terhadap keputusan pembelian Cafe Wapres JK Pemalang.

H4: Terdapat pengaruh store atmosfer, persepsi harga dan kualitas secara simultan pelayanan terhadap keputusan pembelian Wapress JK Pemalang.

\section{METODOLOGI PENELITIAN}

\subsection{Populasi}

Menurut Sugiyono (2012:115)

Populasi adalah wilayah generalisasi yang terdiri atas obyek/subyek yang mempunyai kualitas dan karakteristik tertentu. Populasi 
dalam penelitian ini adalah konsumen Cafe Wapress JK Pemalang.

\subsection{Sampel}

Karena populasi dalam penelitian ini adalh seratus orang responeden maka. Teknik pengambilan sampel yang akan digunakan yaitu Purposive Sampling. Teknik pemilihan sampel berdasarkan penilaian pribadi terhadap responden yang paling memungkinkan untuk menjawab pertanyaan penelitian kita sesuai dengan tujuan penelitian. Adapun penetapan ukuran sampel dalam penelitian ini menggunakan rumus Purba (Sujarweni, 2015: 115), yaitu :

$$
n=\frac{z^{2}}{4(m o \theta)^{2}}
$$

Keterangan:

$\mathrm{n} \quad=$ Jumlah sampel

$\mathrm{Z}$ = Tingkat keyakinan dalam penentuan sampel $(95 \%=1,96)$

Moe $=$ margin of error kesalahan maksimum yang bias ditolerir sebesar $10 \%$ dengan rumus diatas, maka diperoleh perhitungan sebagai berikut:

$n=\frac{1,96^{2}}{4(0,1)^{2}}=96,04$

Berdasarkan perhitungan rumus diatas, maka jumlah responden yang akan dijadikan sampel penelitian adalah sebanyak 96,04 orang, yang akan dibulatkan menjadi 100 orang.

\subsection{Metode Pengumpulan Data}

Guna memperoleh data yang valid dan akurat, teknik pengumpulan data yang dilakukan dalam penelitian ini adalah dengan menggunakan kuesioner. Data primer ini merupakan data yang diperoleh langsung dari obyek penelitian yaitu pada mahasiswa ekonomi dan bisnis ups Tegal. Data primer tersebut dikumpulkan menggunakan kuesioner. Teknik pengumpulan data yang berupa daftar pertanyaan atau pernyataan yang diajukan kepada responden.

\subsection{Teknik Penguji Instrumen Penelitian Uji Validitas}

Menurut Ghozali (2018:51-52) Uji validitas digunakan untuk mengukur sah atau valid tidaknya suatu kuesioner. Menurut Ghozali (2012:52) Suatu kuesioner dikatakan valid jika pertanyaan pada kuesioner mampu untuk mengungkap sesuatu yang akan diukur oleh kuesioner tersebut. Alat untuk mengukur validitas dapat digunakan SPSS (Statistical Product and Service Solutions). Jika $r$ hitung lebih besar dari $r$ tabel dan nilainya positif, maka pertanyaan atau indikator tersebut dinyatakan valid (Ghozali, 2018:52).

\subsection{Uji Reliabilitas}

Menurut Nunnaly (2006) Realiabilitas adalah alat untuk mengukur suatu kuesioner yang merupakan indikator dari variabel atau konstruk. Menurut Ghozali (2011) Suatu kuesioner dikatakan reliabel atau handal jika jawaban seseorang terhadap pertanyaan adalah konsisten atau stabil dari waktu ke waktu Dalam mengukur realibilitas dengan uji statistik Cronbach Alpha ( $\alpha$ ), dapat juga menggunakan alat bantu program komputer yaitu SPSS. Suatu konstruk atau variabel dikatakan reliabel jika memberikan nilai Cronbach Alpha > 0.70 (Nunnally dalam Ghozali, 2018:48).

\subsection{Teknik Analisis Data} Analisis Koefisien Korelasi Rank Spearman

Analisis ini bertujuan untuk mengetahui ada tidaknya pengaruh antara variabel Trust (X1), website quality (X2), dan orientasi belanja (X3) terhadap minat beli (Y) secara parsial. Adapun rumus yang digunakan adalah sebagai berikut (Sugiyono, 2012: 357):

$\rho=1-\frac{6 \sum b_{i}^{2}}{n\left(n^{2}-1\right)}$

Dimana: 
$\rho \quad$ :Koefisien korelasi Spearman Rank $\sum b_{i}{ }^{2}$ :total kuadrat selisih antar ranking

$\mathrm{n} \quad$ : Jumlah sampel yang diteliti

\subsection{Uji z}

Uji z digunakan untuk menguji pengaruh variabel bebas terhadap variabel terikat secara parsial atau individual. Jika nilai Sig. uji t $<0,05$ maka variabel bebas memiliki pengaruh signifikan terhadap variabel terikat secara parsial (Sugiyono 2012:250).

\subsection{Analisis Koefisien Korelasi Berganda}

Analisis korelasi berganda bertujuan untuk mengetahui kuat tidaknya hubungan beberapa variable bebas terhadap variable tererikat. Adapun rumus yang digunakan adalah sebagai berikut:

$$
\left(1-r_{y, 12 \mathrm{a}}^{2}\right)=\left(1-r_{y 1}^{2}\right)\left(1-r_{y 2,1}^{2}\right)\left(1-r_{y \text { a.12 }}^{2}\right)
$$

Keterangan :

$r_{y 2,1}=\frac{r_{y 2}-\left(r_{y 1}\right)\left(r_{21}\right)}{\sqrt{\left(1-r_{y 1}^{2}\right)\left(1-x_{12}^{2}\right)}}$

$r_{y a .12}=\frac{r_{y a .2}-\left(r_{y 1.2}\right)\left(r_{1 a, 2}\right)}{\sqrt{\left(1-r_{y 1.2}^{2}\right)\left(1-x_{1 \mathrm{a} .2}^{2}\right)}}$

$r_{y a, 2}=\frac{r_{y a}-\left(r_{y 2}\right)\left(r_{a 2}\right)}{\sqrt{\left(1-r_{y 2}^{2}\right)\left(1-r_{a 2}^{2}\right)}}$

$r_{y 1,2}=\frac{r_{y 1}-\left(r_{y 2}\right)\left(r_{12}\right)}{\sqrt{\left(1-r_{y 2}^{2}\right)\left(1-x_{12}^{2}\right)}}$

$r_{1 \mathrm{a}, 2}=\frac{r_{1 \mathrm{a}}-\left(r_{12}\right)\left(r_{\mathrm{an}}\right)}{\sqrt{\left(1-r_{12}^{2}\right)\left(1-r_{a 2}^{2}\right)}}$

\subsection{Uji F}

Uji $F$ digunakan untuk menguji seberapa bisa variabel bebas memprediksi varibel terikat. Jika nilai Sig. Menurut (Sugiyono \& Susanto, 2015:202) uji F < 0,05 maka variabel bebas memiliki pengaruh signifikan terhadap variabel terikat secara simultan.

\subsection{Analisis Koefisian Determinasi}

Koefisien Determinasi digunakan untuk menyatukan besar atau kecilnya kontribusi (sumbangan langsung) X1, X2, dan X3 secara bersama-sama terhadap Y. Adapun koefisien determinasi adalah sebagai berikut:

$\mathrm{D}=\mathrm{r} 2 \times 100 \%$

Keterangan :

$\begin{array}{ll}\mathrm{D}= & \text { Koefisien Determinasi } \\ \mathrm{R}= & \text { Koefisien korelasi berganda }\end{array}$

\section{HASIL DAN PEMBAHASAN 4.1 Uji Validitas}

Jumlah butir pernyataan tiap variabel sebanyak 10 butir pernyataan, sebelum dilakukan penelitian kepada 100 responden dilakukan uji validitas dengan 30 orang diluar responden terlebih dahulu, untuk mengetahui kuesioner valid atau tidaknya dengan taraf signifikan $5 \%$ atau 0,05 dan $(\mathrm{N}=30)$ maka didapat $\mathrm{r}_{\text {tabel }}$ sebesar 0,361. Dari hasil analisis ke 8 butir pernyataan tersebut setelah dilakukan perhitungan dengan menggunakan rumus Product Moment Coefficient of Correlation dibantu aplikasi SPSS versi 22 ternyata ke 10 pernyataan dikatakan valid. Karena hasil $r_{\text {hitung }}>r_{\text {tabel }}$. Dengan demikian 10 butir pernyataan tesebut layak digunakan untuk mengumpulkan data penelitian tiap variabel.

\subsection{Reliabilitas}

Instrumen penelitian dapat dapat dikatakan memiliki reliabilitas dalam penelitian apabila memiliki angka Alpha Croncbach > 0.70 (Nunnally dalam Ghozali, 2018:48). Adapun hasil dari pengolahan data penelitian dengan menggunakan program SPSS versi 22, menunjukan adanya realiabilitas instrumen penelitian yaitu memiliki angka alpha corbach variabel keputusan pembelian 0.898, alpha cronbach variabel store atmosfer 0.789, alpha cronbach variabel persepsi harga 0.914 dan alpha corbach variabel kualitas pelayanan 0.865 . 


\subsection{Analisis Koefesien Korelasi Rank Spearman}

Berdasarkan hasil perhitungan koefisien korelasi rank spearman variabel store atmosfer diperoleh nilai rs sebesar 0,670. Nilai rs sebesar 0,670 lalu diinterprestasikan dengan tabel interprestasi nilai $r$ berada pada interval 0,600 0,799 . Hal ini artinya hubungan store atmosfer dengan keputusan pembelian tergolong kuat dan bersifat positif. Positif artinya jika store atmosfer $\left(\mathrm{X}_{1}\right)$ meningkat maka keputusan pembelian (Y) cafe wapress jk pemalang juga ikut meningkat, sebaliknya jika store atmosfer $\left(\mathrm{X}_{1}\right)$ menurun maka keputusan pembelian (Y) cafe wapress jk pemalng juga ikut menurun dan berdasarkan hasil perhitungan koefisien korelasi Rank Spearman variabel persepsi harga diperoleh nilai rs sebesar 0,777. Nilai rs sebesar 0,777 lalu diinterprestasikan dengan tabel interprestasi nilai $r$ berada pada interval $0,600-0,799$. Hal ini artinya hubungan persepsi harga dengan keputusan pembelian kuat dan bersifat positif. Positif artinya jika persepsi harga $\left(X_{2}\right)$ meningkat maka keputusan pembelian (Y) cafe wapress jk pemalang juga ikut meningkat, sebaliknya jika persepsi harga $\left(\mathrm{X}_{2}\right)$ menurun maka keputusan pembelian ( $\mathrm{Y}$ ) cafe wapress $\mathrm{jk}$ pemalang juga ikut menurun dan berdasarkan hasil perhitungan koefisien korelasi Rank Spearman variabel kualitas pelayanan diperoleh nilai rs sebesar 0,710 . Nilai rs sebesar 0,710 lalu diinterprestasikan dengan tabel interprestasi nilai $r$ berada pada interval $0,600-0,799$. Hal ini artinya hubungan kualitas pelayanan dengan minat beli tergolong kuat dan bersifat positif. Positif artinya jika kualitas pelayanan $\left(\mathrm{X}_{3}\right)$ meningkat maka keputusan pembelian (Y) cafe wapress jk pemalamg juga ikut meningkat, sebaliknya jika kualitas pelayanan $\left(\mathrm{X}_{3}\right)$ menurun maka keputusan pembelian (Y) cafe wapress jk pemalang juga ikut menurun.

\subsection{Uji z}

Dari perhitungan $Z_{\text {hitung }}$ variabel store atmosfer diperoleh nilai sebesar 6,666 yang kemudian dibandingkan dengan $Z_{\text {tabel }} 1,96$ yang ternyata $Z_{\text {hitung }}=$ $6,666>Z_{\text {tabel }}=1,96$ dengan demikian hipotesis nol ditolak dan hipotesis alternatif diterima. Artinya terdapat hubungan yang signifikan antara store atmosfer dengan keputusan pembelian cafe wapress $\mathrm{jk}$ pemalang, dan hasil perhitungan $\mathrm{Z}_{\mathrm{hitung}}$ variabel persepsi harga diperoleh nilai sebesar 7,731 yang kemudian dibandingkan dengan $Z_{\text {tabel }} 1,96$ yang ternyata $Z_{\text {hitung }}=7,731>Z_{\text {tabel }}=1,96$ dengan demikian hipotesis nol ditolak dan hipotesis alternatif diterima. Artinya terdapat hubungan yang signifikan antara persepsi harga dengan keputusan pembelian cafe wapress jk pemalag, dan hasil perhitungan $Z_{\text {hitung }}$ variabel kualitas pelayanan diperoleh nilai sebesar 7,064 yang kemudian dibandingkan dengan $Z_{\text {tabel }}$ 1,96 yang ternyata $Z_{\text {hitung }}=7,064>Z_{\text {tabel }}=$ 1,96 dengan demikian hipotesis nol ditolak dan hipotesis alternatif diterima. Artinya terdapat hubungan yang signifikan antara kualitas pelayanan dengan keputusan pembelian cafe wapress $\mathrm{jk}$ pemalang.

\subsection{Analisis Korelasi Berganda}

Dari hasil perhitungan korelasi berganda diperoleh nilai $\mathrm{R}=0,789$. Nilai sebesar 0,789 berada di interval koefisien korelasi $0,600-0,789$. Hal ini artinya menunjukan hubungan yang tergolong kuat antara variabel store atmosfer, persepsi harga dan kualitas pelayanan secara simultan dengan keputusan pembelian variabel store atmosfer, persepsi harga dan kualitas pelayanan cafe wapress $\mathrm{jk}$ pemalang. Hubungan secara simultan dengan keputusan pembelian bersifat positif. Positif artinya jika store atmosfer $\left(\mathrm{X}_{1}\right)$, persepsi harga $\left(\mathrm{X}_{2}\right)$ dan kualitas pelayanan $\left(\mathrm{X}_{3}\right)$ meningkat keputusan pembelian ( $\mathrm{Y}$ ) cafe wapress $\mathrm{jk}$ pemalang juga ikut meningkat, sebaliknya jika store atmosfer $\left(\mathrm{X}_{1}\right)$, persepsi harga 
$\left(\mathrm{X}_{2}\right)$ dan kualitas pelayanan $\left(X_{3}\right)$ menurun keputusan pembelian (Y) cafe wapress $\mathrm{jk}$ pemalang juga ikut menurun.

\subsection{Uji F}

Dari hasil uji koefisien korelasi berganda diatas terdapat nilai $F_{\text {hitung }}$ sebesar 79,81, nilai $F_{\text {hitung }}$ sebesar 79,81 tersebut selanjutnya dibandingkan dengan nilai $F_{\text {tabel }} 3,09$. Karena $F_{\text {hitung }}>F_{\text {tabel }}(79,81$ $>$ 3,09) artinya ada pengaruh yang signifikan antara store atmosfer, persepsi harga dan kualitas pelayanan secara simultan cafe wapress $\mathrm{jk}$ pemalang. Sehingga hipotesis yang menyatakan bahwa "terdapat pengaruh store atmosfer, persepsi harga dan kualitas pelayanan yang signifikan antara simultan terhadap kepitusan pembelian cafe wapress $\mathrm{jk}$ pemalang" dapat diterima.

\subsection{Analisis Koefisien Determinasi}

Koefisien determinasi digunakan untuk menyatakan besar atau kecilnya kontribusi (sumbangan langsung) antara trust, website quality dan orientasi belanja secara bersama-sama terhadap minat beli. Maka dapat diperoleh nilai koefesien determinasi sebagai berikut:

\subsubsection{Hubungan persepsi harga dengan keputusan pembelian}

jk pemalang. Diperoleh nilai $\mathrm{rs}_{\mathrm{xy}}$ sebesar 0,777 yang berada pada interval koefesien korelasi 0,600-0,7999 dengan uji signifikasi koefisien dengan koefesien determinasi sebesar 0,6225. Berarti keragaman total yang di jelaskan model pengaruh store atmosfer, kualitas pelayanan dan keputusan pembelian secara bersamasama. Sedangkan sisanya sebesar $27,75 \%$ oleh faktor lain yang tidak bisa dijelaskan rank spearman diperoleh nilai $\mathrm{Z}_{\text {hitung }}$ sebesar 7,731 Sehingga dapat disimpulkan bahwa terdapat hubungan yang kuat dan signifikan antara persepsi harga dengan

$$
\begin{aligned}
& \mathrm{D}=\mathrm{R}^{2} \times 100 \% \\
& \mathrm{D}=(0,789)^{2} \times 100 \% \\
& \mathrm{D}=0,622521 \times 100 \% \\
& \mathrm{D}=62,25 \%
\end{aligned}
$$

Besarnya koefesien determinasi berdasarkan analisis di atas yaitu sebesar 0,6225 . Berarti keragaman total yang di jelaskan model pengaruh store atmosfer, kualitas pelayanan dan keputusan pembelian secara bersama-sama terhadap minat beli adalah sebesar 62,25,6\% . Sedangkan sisanya sebesar $27,75 \%$ oleh faktor lain yang tidak bisa dijelaskan.

\subsection{Pembahasan}

\subsubsection{Hubungan store atmosfer dengan keputusan pembelian}

Diperoleh nilai $\mathrm{rs}_{\mathrm{xy}}$ sebesar 0,670 yang berada pada interval koefisien korelasi 0,600-0,799, dengan uji signifikasi koefisien korelasi rank spearman diperoleh nilai $Z_{\text {hitung }}$ sebesar 6,666 . Sehingga dapat disimpulkan bahwa terdapat hubungan yang kuat dan signifikan antara store atmosfer dengan keputusan pembelian di cafe wapress $\mathrm{jk}$ pemalang.

Pengujian hipotesis kedua betujuan untuk menguji hubungan persepsi harga dengan keputusan pembelian cafe wapres

keputusan pembelian cafe wapress $\mathrm{jk}$ pemalang.

\subsubsection{Hubungan kualitas pelayanan dengan keputusan pembelian \\ Pengujian hipotesis ketiga betujuan} untuk menguji hubungan kualitas pelyanan dengan keputusan pembelian cafe wapress $\mathrm{jk}$ pemalang. Diperoleh nilai $\mathrm{rs}_{\mathrm{xy}}$ sebesar 0,710 dengan uji signifikasi koefesien korelasi rank spearman diperoleh nilai

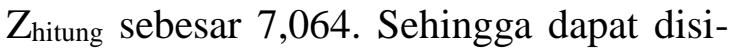
mpulkan bahwa terdapat hubungan yang kuat dan signifikan antara kualitas pelayanan dengan keputusan pembelian cafe wapress jk pemalang. 


\subsubsection{Hubungan store atmosfer, persepsi harga dan kualitas pelayanan Secara Bersama - sama dengan keputusan pembelian}

Pengujian hipotesis keempat betujuan untuk menguji hubungan antara store atmosfer, persepsi harga dan kualitas pelayanan secara bersama - sama terhadap keputusan pembelian cafe wapress $\mathrm{jk}$ pemalang dengan menggunakan alat analisis korelasi berganda. Diperoleh nilai koefisien korelasi (R) sebesar 0, 789 yang berada pada interval koefisien korelasi $0,600-0,799$, dengan signifikansi sebesar $F_{\text {hitung }}>F_{\text {tabel }}(79,81>3,09)$, yang menyatakan terdapat hubungan yang positif dan signifikan secara bersama sama antara store atmosfer, persepsi harga dan kualitas pelayanan terhadap keputusan pembelian pada cafe wapress $\mathrm{jk}$ pemalang. Pada penelitian ini dapat disimpulkan terdapat hubungan yang signifikan antara store atmosfer, persepsi harga dan kualitas pelayanan secara bersama - sama terhadap keputusan pembelian cafe wapress $\mathrm{jk}$ pemalang

\section{KESIMPULAN DAN SARAN 5.1 Kesimpulan}

1. Adanya pengaruh antara store atmoser terhadap keputusan pembelian adalah sebesar 0,670 dan dan Zhitung > Ztabel yaitu 6,666> 1,96, maka Ho ditolak. Nilai positif tersebut menunjukan pengaruh yang searah, artinya jika store atmosfer mengalami peningkatan, maka keputusan pembelian juga mengalami peningkatan. Begitu juga sebaliknya jika store atmosfer mengalami penurunan, maka keputusan pembelian juga mengalami penurunan.

2. Adanya pengaruh antara persepsi harga terhadap keputusan pembelian adalah sebesar 0,777 dan dan Zhitung > Ztabel yaitu 7,731>
1,96, maka Ho ditolak. Nilai positif tersebut menunjukan pengaruh yang searah, artinya jika persepsi harga mengalami peningkatan, maka keputusan pembelian juga mengalami peningkatan. Begitu juga sebaliknya persepsi harga mengalami penurunan, maka keputusan pembelian juga mengalami penurunan.

3. Adanya pengaruh antara kualitas pelayanan terhadap keputusan pembelian adalah sebesar 0,710 dan dan Zhitung > Ztabel yaitu 7,064> 1,96, maka Ho ditolak. Nilai positif tersebut menunjukan pengaruh yang searah, artinya jika kualitas pelayanan mengalami peningkatan, maka keputusan pembelian juga mengalami peningkatan. Begitu juga sebaliknya jika kualitas pelayanan mengalami penurunan, maka keputusan pembelian juga mengalami penurunan.

4. Adanya pengaruh antara store atmosfer, persepsi harga dan kualitas pelayanan secara simultan terhadap keputusan pembelian, dimana nilai koefisien korelasi berganda (R) yang ditunjukkan adalah sebesar 0,789 serta nilai 79,81 (Fhitung) > 3,09 (Ftabel). Nilai tersebut merupakan pengaruh yang sangat kuat dan postif. Artinya jika nilai variabel store atmosfer, persepsi harga dan kualitas pelayanan bersama-sama mengalami kenaikan maka akan diikuti juga dengan kenaikan keputusan pemebelian dan sebaliknya.

\subsection{Saran}

Sesudah melakukan penelitian, analisis data, dan merumuskan kesimpulan dari hasil penelitian yang dilakukan untuk dijadikan masukan dan pertimbangan. Adapun saran - saran yang dapat diberikan 
melalui hasil penelitian ini adalah sebagai berikut :

1) Berkaitan dengan store atmosfer atau kepercayaan, pihak Memasang foto/gambar yang menambah kesan tertentu secara tematik. Memainkan musik sesuai suasana (alunan musik yang lembut seperti Kenny $\mathrm{G}$ atau Kitaro yang tenang dan nyaman di dalam toko akan kontras dengan suasana panas terik di luar sehingga membuat orang betah dan nyaman berada di dalam cafe).

2) Berkaitan dengan persepsi harga, tidak dianjurkan menuliskan harga dalam menu sewaktu-waktu dapat berubah.Perusahaan dapat menggunakan beberapa teknik penetapan harga untuk merangsang pembelian (menuliskan harga $\mathrm{Rp}$ 10.000 dengan $\mathrm{Rp} 10 \mathrm{~K}$ ). Perusahaan terus berupaya menyesuaikan dengan dinamika pasar agar harga terus bersaing dengan perusahaan pesaing.

3) Berkaitan dengan kualitas pelayanan, Menghindari pelayanan yang tidak ramah. Pelayanan harus lebih menghargai pelanggan.Harus menghindari kesalahan dalam pelayanan. Produk harus sesuai dengan ekspektasi konsumen (produk yang ada di gambar harus sama dengan produk yang di berika

\section{DAFTAR PUSTAKA}

Adisaputro, Gunawan dan Marwan Asri. 2013. Anggaran Perusahaan. Edisi ke 2.Yogyakarta:BPFE.

Ariefianto, Doddy Moch. 2012. Ekonometrika. Jakarta : Erlangga.

Blake, Reed H dan Edwin O Haroldsen. 2003. Taksonomi Konsep Komunikasi. Surabaya : Papyrus Surabaya.
David, R Fred dan Forest R David. 2016. Manajemen Strategik:Suatu Pendekatan Keunggulan Bersaing.Edisi ke 15.Jakarta Selatan: Salemba Empat.

Fahimah, DH Fauzi dan Hidayat Kadarisman. 2015. "Pengaruh Store Atsmosfer (Suasana Toko) Terhadap Keputusan Pembelian" Vol. 28, No.2, November 2015 hal 1-10.

Ghozali, Imam. 2012. Aplikasi Multivariate dengan Program SPSS. Badan Semarang: Penerbit Universitas Diponegoro.

Hartman, Laura P dan Joe Desjardins. 2011. Etika bisnis (Pengambilan Keputusan untuk Integritas Pribadi \& Tanggung Jawab Sosial). Jakarta : Erlangga.

Hesmu Nurcahyo, Brian dan Khasanah, Imroatul. 2016. "Analisis Pengaruh Persepsi Harga, Kualitas Pelayanan, Lokasi, dan Word of Mouth Terhadap Keputusan Pembelian (Studi pada Taman Joglo Cafe Semarang)". Vol. 5, No.3, February 2016 hal 1-16.

H.S. Bernando dan Prayoga K, Arief Bowo. 2015. "Pengaruh Persepsi Harga dan Promosi Terhadap Keputusan Pembelian Konsumen Produk ENERVON-C". Vol. 1, No. 3, November 2015 hal 1- 13.

Kotler, Philip dan Kevin Keller. 2009. Manajemen Pemasaran Edisi Ketiga Belas Jilid 1. Jakarta : Erlangga.

Kotler, Philip dan Kevin Keller. 2009. Manajemen Pemasaran. Edisi 
Ketiga Belas Jilid 2. Jakarta : Erlangga.

Mulyana, Yana. 2018. Komunikasi Bisnis. Tegal : YM.

Sudana, I Made. 2015. Manajemen Keungan Perusahaan. Edisi Kedua. Jakarta Erlangga.
Sujana, Asep ST. 2012. Manajemen Minimarket Jakarta: Raih Asa Sukses (Penebar Swadaya Grup)

Sugiyono. 2012. Metode Penelitian Bisnis. Bandung: Alfabeta

Webster dan Windd 2009. Manajemen Pemasaran Edisi Ketiga Belas Jilid 1. Jakarta : Erlangga. 